is basically an academic development, we can build on what has been achieved already, enabling family doctors of the future to become more fully prepared for their chosen career. Without it, without vocational training, we will find it difficult to maintain our present level.I am, etc.,

Penketh, Lancs.

TeViot EimerL.

SIR,-Many misunderstandings have crept into the correspondence. Before it closes may I help to clarify the issue? The real question is: Shall the College stiffen its criteria for entry to membership? What is proposed is that there shall be a further test for the younger potential member.

There is already a test for membership. Applicants, besides having to be registered an appropriate time, have to have two sponsors who are themselves members, and they may be interviewed by the College board of censors.

It is proposed that in future those who registered after 1961 , in addition to needing sponsors and being interviewed by the board, shall undergo a further test. No change in the criteria for membership is proposed for those who registered before 1961 - that is, those already established in practice.

The young potential entrant will have to show proof of satisfactory hospital experience and he will have to have had two years' experience in a general practice. In addition he will have to perform one of the three following tests: (1) submit a thesis or published work relevant to general practice, or (2) present reports of patients seen in general practice, or (3) pass an examination relevant to general practice.

It is hoped that (1) or (2) will be the commonly used methods and that (3), the "examination," will atrophy from disuse, so setting an example to our brethren in the other colleges.

There are complex reasons why the amendment of our constitution to stiffen the criteria for entry to membership has to be approved at three successive annual general meetings of the members of the College. It was so approved in 1961 and 1962. I hope that the A.G.M. of 1963 will finally confirm this decision.-I am, etc.

London W.12. Stuart Carne.

\section{Rickettsial Endocarditis}

SIR,-The clinicopathological conference reported in your recent issue (April 27, p. 1143) brings to a total of eight the reported cases of Q-fever endocarditis proved by a combination of serological tests, histological demonstration of rickettsiae in diseased heart valves, and isolation of $R$. burneti from the valves of all seven cases investigated for this purpose. ${ }^{123}$ The clinical features of these cases resemble closely those of rickettsial endocarditis following typhus reviewed by Worms ${ }^{4}$ - for example, an excess of males over females, predominant affection of the aortic valves, development of heart failure with nephritis and other visceral symptoms, obstructions of peripheral arteries, and increased gamma globulins. As in Q-fever endocarditis, blood cultures were usually negative, penicillin therapy ineffective, and the prognosis grave.

The uniformly fatal character, to date, of Q-fever endocarditis presents a challenge which is difficult to meet on the basis of the limited information available from the few cases yet recognized. It is therefore important that all cases of subacute infective endocarditis with repeatedly negative blood cultures should be tested for Q-fever antibodies. If the usual complement-fixation test with phase 2 antigen is positive, tests with phase 1 antigen may confirm the chronic nature of the infection. Since Dr. C. M. Fletcher informs me that case 246550 presented by him at the clinicopathological conference had both phase 1 and phase 2 antibodies, reactivity with phase 1 antigen has been found in seven of the reported cases, the single exception having had the unusually short duration of four months from onset to death. ${ }^{5}$ Full clinical and epidemiological histories of positive cases should be recorded, and in the event of death detailed necropsy should be carried out with full precautions against infection of staff. Where possible, isolation of rickettsiae from specimens of blood and urine may be attempted during life, and from heart valves and other tissues after death.

Though the studies of Marmion and colleagues ${ }^{6}$ and our own limited investigations in Glasgow do not suggest that Q-fever is a common cause of endocarditis in Britain, insufficient information is yet available to assess the frequency of this grave complication of an infection that is widespread throughout the country. ${ }^{7}$ Better understanding of the problem requires clinical awareness of the possibility of Q-fever as a cause of endocarditis and the collection of blood for the simple serological test which is appropriate.-I am, etc.,

University of Glasgow.

NoRMAN R. GRIST.

\section{REFERENCES}

Smith, W. G., and Evans, A. D., Lancet, 1960, 2, 846

Ferguson, I. C., Craik, J. E., and Grist, N. R., J. clin. Path., $1962,15,235$

Glick, L., Edwards, A. T. and Marmion, B. P. 1961 (cited by Marmion, B. P. J. Ḧy. E pidem. (Praha), 1962, 6, 79

Worms, R., Rev. Prat. (Paris), 1956, 6, 1309

Evans, A. D., Powell, D. E. B., and Burrell, C. D., Lancet, $1959,1,864$

Marmion, B. P., Higgins, F. E., Bridges, J. B., and Edwards, A. T., Brit. med. J., $1960,2,1264$.

A. and Stoker, M. G. P., Brit. med. J., 1958, 2, 809.

\section{Anaesthesia and Forceps Delivery}

SIR,-All obstetricians will agree with Mr. P. J. Huntingford (May 4, p. 1195) that local analgesia for forceps delivery carries less risk for the mother. What is not established, however, is that general anaesthesia carries an increased risk for the baby. It is true that the perinatal mortality is higher in forceps deliveries performed under general anaesthesia, but this is surely due to the fact that it is the more difficult forceps cases that are dealt with under general anaesthesia. One cannot compare the foetal results of forceps delivery under general anaesthesia and pudendal block, because the cases selected for each method are not comparable.

In St. Luke's Hospital, Bradford, in 1961 and 1962 there were 674 forceps deliveries, $9.8 \%$ of the total of 6,843 deliveries. Of the 674 , some $510(75.7 \%)$ were performed under pudendal block and 164 (24.3\%) under general anaesthesia. A total of 17 babies died:

\begin{tabular}{|c|c|c|}
\hline & Pud & ndal Block \\
\hline $\begin{array}{l}\text { Major congenital abnorma } \\
\text { Intrauterine death befor }\end{array}$ & ality $\ldots$ & 3 \\
\hline delivery commenced & $\begin{array}{l}\text { e forceps } \\
\ldots\end{array}$ & 4 \\
\hline $\begin{array}{l}\text { Prematurity } \ldots \\
\text { Intracranial haemorrhage }\end{array}$ & . & 1 \\
\hline Intracranial haemorrhage & . & 2 \\
\hline & Total & 10 \\
\hline
\end{tabular}

There is thus no suggestion that general anaesthesia per se contributes to perinatal mortality in babies delivered by forceps. There is an increased incidence of non-fatal neonatal asphyxia, but it has already been 